\title{
Percepção de saúde de adolescentes de comunidade rural: entre o ideal e o real
}

\author{
The health perception rural community adolescents: between the ideal and the real
}

Percepción de salud de adolescentes de comunidad rural: entre lo ideal y lo real

Anny Giselly Milhome da Costaํ, Izaildo Tavares Luna², Adna de Araújo Silva ${ }^{3}$, Jaislâny de Sousa Mesquita Patrícia Neyva da Costa Pinheiro ${ }^{5}$, Neiva Francenely Cunha Veira ${ }^{6}$

\footnotetext{
${ }^{1}$ Enfermeira, Mestre em Enfermagem. Discente do Programa de Pós-Graduação em Enfermagem, nível Doutorado, da Universidade Federal do Ceará (UFC). Professora Auxiliar da Universidade Federal de Sergipe. Lagarto, SE, Brasil. E-mail: annygiselly@yahoo.com.

${ }^{2}$ Enfermeiro, Mestre em Enfermagem. Discente do Programa de Pós-Graduação em Enfermagem, nível Doutorado, da UFC. Fortaleza, CE, Brasil. E-mail: izaildo@yahoo.com.br.

${ }^{3}$ Enfermeira. Discente do Programa de Pós-Graduação em Enfermagem, nível Mestrado, da UFC. Fortaleza, CE, Brasil. E-mail: adnaaraujo@yahoo.com.br.

${ }^{4}$ Enfermeira. Fortaleza, CE, Brasil. E-mail: jaislanymesquita@hotmail.com.

${ }^{5}$ Enfermeira, Doutora em Enfermagem. Professora Adjunta da UFC. Fortaleza, CE, Brasil. E-mail: neyva.pinheiro@yahoo.com.br.

${ }^{6}$ Enfermeira, Doutora em Educação em Saúde. Professora Associada da UFC. Fortaleza, CE, Brasil. E-mail: neivafrancenely@hotmail.com.
}

\section{RESUMO}

Estudo exploratório-descritivo, de abordagem qualitativa, desenvolvido por meio de Pesquisa Participante Baseada na Comunidade cujo objetivo principal foi compreender a percepção de saúde de adolescentes de uma comunidade rural. Utilizouse a técnica de grupo focal e o registro em diário de campo para obtenção dos dados com 26 adolescentes de uma comunidade rural. Os resultados foram analisados e interpretados qualitativamente, expressos mediante duas categorias temáticas que evidenciaram a concepção ideal e real de saúde dos adolescentes. Na perspectiva desse grupo, a saúde do adolescente na comunidade rural é determinada por aspectos positivos e negativos, o que reflete a percepção de saúde e de doença destes. Conclui-se que a enfermagem poderá reduzir a distância observada entre a saúde ideal e a real na comunidade rural ao apropriar-se da abordagem sociocultural do adolescer e desenvolver ações intersetoriais que promovam condições sanitárias satisfatórias e estimulem o potencial do adolescente como ator social.

Descritores: Adolescente; População Rural; Saúde Pública; Educação em Saúde; Enfermagem em Saúde Comunitária.

\section{ABSTRACT}

This qualitative exploratory-descriptive study was performed by means of the Community Based Participant Research. The main objective was to understand the health perception of adolescents from a rural community. The focal group and field journal techniques were used to collect data from 26 adolescents of a rural community. The results were analyzed and qualitatively interpreted, expressed through two thematic categories that showed the ideal and real health conception of the adolescents. From this group's perspective, the health of rural community adolescents is determined by positive and negative aspects, with reveal their perception of health and disease. It is concluded that nursing can reduce the distance between the ideal and real health in the rural community by taking hold of the sociocultural approach of becoming adolescent and developing intersectoral interventions to promote satisfactory sanitary conditions and encourage the adolescent's potential as a social actor.

Descriptors: Adolescent; Rural Population; Public Health; Health Education; Community Health Nursing.

\section{RESUMEN}

Estudio exploratorio-descriptivo, de abordaje cualitativo, desarrollado mediante Investigación Participante Basada en la Comunidad, que objetivó comprender la percepción de salud de adolescentes de una comunidad rural. Se utilizó técnica de grupo focal registrada en diario de campo para obtener los datos sobre muestra de 26 adolescentes de una comunidad rural. Los resultados fueron analizados e interpretados cualitativamente, expresados según dos categorías temáticas que evidenciaron la concepción ideal y real de salud de los adolescentes. En la perspectiva del grupo, la salud del adolescente en la comunidad rural resulta determinada por aspectos positivos y negativos, ello refleja su percepción de salud y enfermedad. Se concluye en que la enfermería podrá reducir la distancia observada entre la salud ideal y la real en la comunidad rural al apropiarse del abordaje sociocultural de la adolescencia y desarrollar acciones intersectoriales promoviendo condiciones sanitarias satisfactorias que estimules el potencial del adolescente como actor social.

Descriptores: Adolescente; Población Rural; Salud Pública; Educación en Salud; Enfermería en Salud Comunitaria. 


\section{INTRODUÇÃO}

A comunidade rural pode ser conceituada como categoria social em contínua transformação, constituída por agregados de pessoas que se conhecem e mantém entre si relações culturais singulares em torno da vida no campo e na natureza(1).

O acesso à saúde em áreas rurais é foco das atuais políticas públicas no Brasil, as quais pretendem ampliar e melhorar o atendimento na atenção primária. O cuidado à saúde rural deve considerar os indicadores locais, a prática dos profissionais de saúde, as características do sistema e o território-processo, envolvendo as dinâmicas de cada área ou região(2).

Além das características locais, as diferenças na percepção de saúde entre os grupos etários podem influenciar a relação saúde/doença na vida pessoal e comunitária. No caso de adolescentes, a percepção positiva da saúde está vinculada a sentimentos de bemestar que reduzem comportamentos de risco à saúde na vida adulta, ou seja, quanto maior a percepção de bemestar durante a adolescência, maiores são as chances de adultos saudáveis(3).

No Brasil, o jovem/adolescente rural deseja melhorias nas áreas de educação, profissionalização e lazer. Relatório nacional afirma que o lazer é praticamente inexistente para adolescentes moradores de zonas rurais ${ }^{(4)}$. Em relação ao atendimento de saúde, observa-se busca ao serviço apenas por livre demanda, caracterizando o ciclo adoecer/curar. Equipes de Saúde da Família apontam a insegurança do profissional de saúde como principal entrave no estabelecimento de vínculos e na relação de cuidado com o adolescente rural ${ }^{(5)}$.

A distância entre profissionais de saúde e adolescentes gera lacunas em temáticas de interesse dos jovens, como sexualidade e Doenças Sexualmente Transmissíveis (DST), considerando que $81,2 \%$ das meninas da zona rural buscam informações sobre sexualidade e, ainda assim, apresentam déficit de conhecimentos sobre o uso do preservativo e as formas de transmissão da Aids ${ }^{(6)}$.

O manejo de condições de saúde tipicamente rurais requerem competências profissionais específicas, como habilidades dialógicas interculturais ${ }^{(2)}$. Neste cenário, o estabelecimento de vínculos entre enfermeiro e adolescente tem seus pilares na família, e sua relação de cuidado é centrada na formação de um sujeito de direitos e deveres que advogará por melhorias da saúde na sua comunidade $^{(7)}$.

Diante desse contexto, enfermeiros sentiram-se motivados a compreender as perspectivas e necessidades de saúde de adolescentes rurais como fenômeno que poderá auxiliar a área da saúde na elaboração de projetos que promovam espaço de reflexão-crítica na construção de soluções positivas para melhoria da saúde e do estabelecimento de vínculos na atenção primária de saúde.

Esta pesquisa foi guiada pelos seguintes questionamentos: como os adolescentes veem a realidade de saúde na comunidade rural? Quais saberes e ações os adolescentes rurais têm em relação à promoção da saúde local? Os objetivos do estudo foram: compreender a percepção de saúde de adolescentes rurais e identificar problemas sociosanitários da comunidade que influenciam a saúde de adolescentes a partir da visão destes.

\section{MATERIAIS E MÉTODOS}

Pesquisa Participante Baseada na Comunidade $\left(^{(P P B C}\right)^{(8)}$ realizada com adolescentes moradores da zona rural Carapió, Estado do Ceará, região Nordeste do Brasil. A PPBC é uma abordagem colaborativa de investigação que envolve pesquisadores, parceiros e membros de comunidades em um processo de reflexão crítica a partir de temas de importância local, identificação de problemas e elaboração de soluções coletivas. Essas pesquisas devem estimular mudanças positivas em saúde, coaprendizado e empowerment(8).

Dados disponibilizados pela Estratégia de Saúde da Família (ESF) do Carapió revelam uma área rural composta por 1.181 habitantes, 327 famílias, 139 adolescentes de 12 a 18 anos de idade - 78 meninas e 61 meninos, 655 imóveis (casas, comércios, terrenos baldios e outros), duas entidades comunitárias efetivamente organizadas (Associação de Moradores e Associação de Agricultores), um grupo informal (atividade física da melhor idade), economia local baseada na agricultura, pequeno comércio de varejo e uma fábrica, dois estabelecimentos públicos (Escola de Ensino Fundamental e UBS), uma Igreja Católica e Igrejas Evangélicas.

Para seleção dos participantes, procurou-se a escola que representou um ponto de apoio à pesquisa e ofereceu população de 80 adolescentes de 12 a 18 anos 
(58\% do total da área). Os pesquisadores divulgaram as intenções da pesquisa para esses adolescentes e distribuíram fichas de inscrições voluntárias.

Após o recebimento de 55 fichas de inscrição, foram aplicados os seguintes critérios de inclusão: ser morador da área, cursar regularmente a escola, apresentar bom desempenho escolar, ter disponibilidade de horário e não apresentar deficiência física e/ou mental que o impedissem de participar da pesquisa. Foram selecionados 26 adolescentes na faixa etária de 12 a 18 anos com base na definição de adolescência do Estatuto da Criança e do Adolescente - ECA ${ }^{(9)}$.

Os participantes foram distribuídos em dois grupos focais, de acordo com as séries escolares, compostos de 13 membros cada um. O número de participantes seguiu recomendações de autores que demonstraram a eficácia de trabalhar com pequenos grupos, de seis a 15 pessoas, pois se tornam mais coesos e produtivos ${ }^{(10)}$.

Durante dois meses, foram realizadas oito sessões de GF, divididas em quatro encontros por grupo. Cada sessão durou uma hora e trinta minutos. As reuniões ocorreram semanalmente na Associação de Moradores do Carapió, construção situada no centro da comunidade.

Após cada encontro, os pesquisadores registraram o curso dos acontecimentos em diário de campo, com a transcrição integral das falas dos participantes. Algumas informações foram registradas pelos adolescentes por meio de desenhos e relatos escritos.

A análise e interpretação dos dados se deram em contexto qualitativo, expressos mediante categorias temáticas. Foram identificadas duas categorias: concepção ideal de saúde dos adolescentes e concepção real de saúde dos adolescentes. O processo de categorização temática junto aos participantes no decorrer da realização dos grupos, seguiu-se o processo do "olhar e ad-mirar" as informações, em um contexto de validação grupal e conscientização(11). A separação do contexto total em partes proporcionou retornar as discussões para o ponto inicial, alcançando, desta maneira, compreensão mais dinâmica de sua significação.

O projeto que deu origem ao estudo foi aprovado pelo Comitê de Ética em Pesquisa da Universidade Federal do Ceará, conforme $n^{\circ}$ de protocolo 09/09. A pesquisa seguiu os princípios éticos e legais da Resolução $n^{\circ} 466 / 12$ do Conselho Nacional de Saúde do Brasil. Os adolescentes e seus pais/responsáveis assinaram o Termo de Consentimento Livre e Esclarecido (TCLE). O anonimato dos participantes foi preservado e as falas foram identificadas pela letra $P$, seguida de um número cardinal $(1,2,3 \ldots)$, sexo (F ou $M)$ e idade.

\section{RESULTADOS E DISCUSSÕES}

Na categoria Concepção ideal de saúde dos adolescentes, os participantes construíram desenhos com itens considerados fundamentais para o adolescente ter saúde na comunidade rural. A partir do título Retrato das coisas principais para um adolescente ter saúde, cada participante retratou os ambientes e as situações que provocaram as discussões no grupo focal.

As três ilustrações da Figura 1 representam uma síntese dos elementos que se repetiram nos grupos, e representam uma síntese geral dos itens identificados como fundamentais para um adolescente ter saúde na comunidade rural.

Figura 1: Desenhos acerca do ideal de saúde do adolescente na comunidade rural.

RETRATO DAS COISAS PRINCIPAIS PARA UM ADOLESCENTE TER SAÚDE:

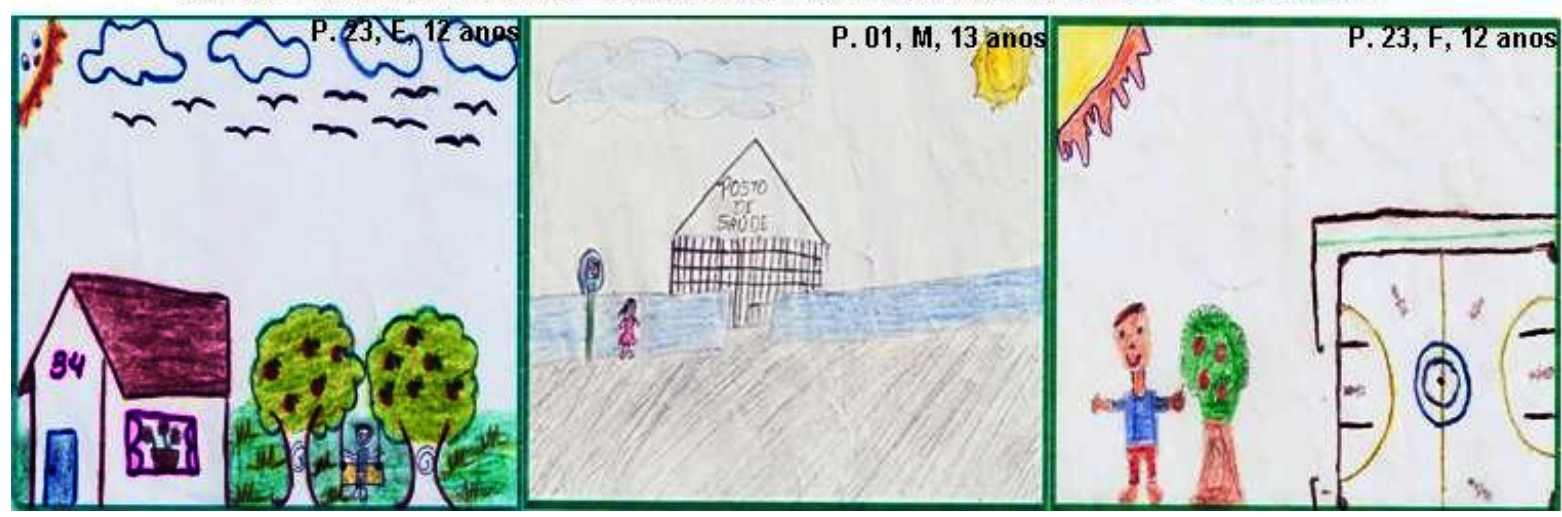

Os desenhos apresentados na Figura 1 podem ser uma casa com um belo jardim, árvores, pássaros, sol e um descritos da seguinte forma: a adolescente P.22 ilustrou jovem/adolescente brincando; P.01 desenhou uma 
adolescente aguardando atendimento médico em frente a um posto de saúde; no desenho de P.23, observou-se um rapaz comendo maçãs diretamente da árvore em um dia ensolarado e um belo campo de futebol para lazer.

A maioria dos participantes caracterizou em desenho o cenário ideal para saúde do adolescente rural com casas, árvores, lazer, amigos, família. A fala de P.23 ilustra a situação:

Para a gente ter saúde precisa respirar um bom ar, viver com a natureza e morar com a nossa família. Eu gosto de ter lazer porque fico mais feliz e tudo dá certo. Mas, a gente tem que ir para escola também e estudar. (P.23, F, 12 anos).

A segunda imagem mais repetida incluiu os locais de atendimento de saúde (UBS e hospital). Quando questionados acerca da importância do hospital para saúde dos adolescentes, os grupos afirmaram que:

Para ter saúde, o jovem precisa de um posto de Saúde que preste e de hospital que atenda ele quando precisar, quando ele tem doença e precisa de médico para se tratar. (P.01, M, 13 anos).

É muito importante ter hospital que tenha muita ficha para se consultar e a gente não voltar doente para casa. (P.26, F, 13 anos).
Outras imagens mostravam a boa alimentação do adolescente na comunidade rural, com frutas, arroz, feijão, carnes. O lazer também foi muito retratado na forma de esportes com campos de futebol e natação. Seguem abaixo as expressões:

Tem que jogar muito futebol para ocupar o tempo e ficar com o corpo saudável. (P. 12, M, 12 anos).

É bom para o adolescente comer coisas saudáveis e evitar besteiras como pipocas e pirulitos. (P.05, F, 13 anos).

Os desenhos e as falas, na maioria dos casos, apontaram visão geral da saúde restrita ao modelo biológico-curativo, com foco em setores de atendimento. O conceito de saúde "como ausência de doenças" prevaleceu na comunidade rural local.

No contexto geral da promoção da saúde, a concepção ideal de saúde dos adolescentes foi classificada como ampliada (positiva) ou tradicional (biomédica). As discussões grupais possibilitaram a construção do Quadro 1 que categoriza as concepções ideais de saúde dos participantes em ampliada ou tradicional.

Quadro 1: Categorização das concepções de saúde ideal dos participantes, segundo a visão ampliada ou tradicional da saúde do adolescente.

\begin{tabular}{|c|c|}
\hline Concepção ampliada & Concepção tradicional \\
\hline Família & Hospital \\
Boa alimentação & Posto de saúde \\
Viver na natureza & Atendimento médico e odontológico \\
Habitação & \\
Esportes & \\
Amizades & \\
Profissionalização & \\
Educação & \\
\hline
\end{tabular}

A saúde está diretamente relacionada aos estados de compreensão, aceitação e adaptação nas situações de vida das pessoas ${ }^{(12)}$. A visão ampliada de saúde está presente no novo paradigma da promoção da saúde e possui a sociedade como foco, isto é, a saúde está intimamente relacionada com o poder de conhecimento e ação de pessoas, grupos e comunidades. Além do corpo individual, a saúde é concebida em corpo social(13).

No contexto geral, de acordo com os grupos, para um adolescente ter saúde, ele precisa de boa moradia e família, boa alimentação, natureza, lazer e esporte, além de atendimento nos postos de saúde e hospitais.

Na categoria Concepção real de saúde, os adolescentes construíram desenhos que retrataram a situação atual de saúde na comunidade rural. A partir do título Retrato do adolescente morador do Carapió, os participantes discutiram criticamente acerca dos elementos desenhados. A Figura 2 representa uma síntese geral da visão de saúde dos adolescentes que moram na área rural. 
Figura 2: Visão da saúde do adolescente que vive na comunidade pesquisada.

\section{RETRATO DA SAÚDE DO ADOLESCENTE MORADOR DO CARAPIÓ:}

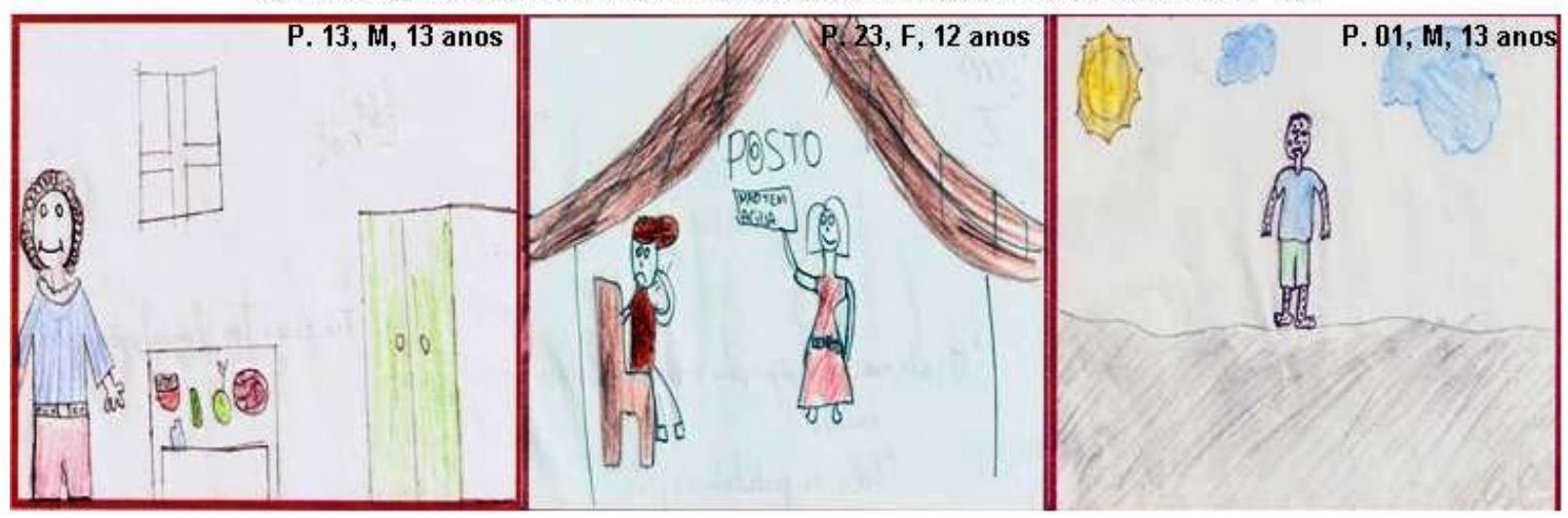

Os desenhos apresentados na Figura 2 podem ser descritos da seguinte forma: o participante 13 ilustrou um jovem/adolescente com uma bela casa, e uma mesa repleta de frutas e verduras; o participante 23 desenhou um adolescente triste e com dor, pois procurou atendimento odontológico e estava faltando água no posto de saúde; no desenho de P.01, observa-se um rapaz triste e doente apesar do belo dia de sol.

A maioria dos participantes ilustrou em desenho o cenário atual da saúde do adolescente na comunidade pesquisada, com doenças e problemas no atendimento de saúde. Como ilustra a fala:

Sempre que vou no posto com o dente doendo não tem ficha porque não tem água. Não sei como um posto tem dentista e não tem água, sem falar que agora não tem nem médico. (P.23, F, 12 anos).

A segunda imagem mais repetida incluiu presença de boa alimentação, adequada moradia e família. Quando questionados acerca da importância da família para saúde dos adolescentes naquela comunidade, os grupos afirmaram que:

Minha mãe sempre cozinha para mim coisas boas, mas a gente é que não quer comer. (P.01, M, 13 anos).

Os jovens têm uma casa boa e boa alimentação, mas têm pessoas que passam fome também aqui. Eu já vi uns meninos pegando lixo para vender e comer. (P.18, F, 14 anos).

A visão dos adolescentes acerca da saúde na comunidade Carapió incluiu as questões: problemas no atendimento de saúde na comunidade, doenças relacionadas à má alimentação e polvição, disparidades sociais e falta de lazer.

Nesse sentido, os participantes discutiram criticamente sobre as características boas e más das situações de vida para o futuro do adolescente. No Quadro 2, as concepções de saúde dos adolescentes foram classificadas de acordo com os aspectos positivos e negativos vivenciados na comunidade rural.

Quadro 2: Categorização das concepções de saúde dos participantes segundo classificação em pontos positivos ou negativos.

\begin{tabular}{|c|c|}
\hline Aspectos positivos & Aspectos negativos \\
\hline Ter família & Ter doenças \\
Possuir boa alimentação & Possuir alimentação ruim \\
Viver na natureza & Existir fome \\
Possuir casa para morar & Conviver com a poluição da natureza \\
Ter amigos & Não ter cursos profissionalizantes \\
Ir para escola & Não ter lazer \\
& Não ter atendimento na UBS \\
& Existir fumantes e alcoolistas \\
\hline
\end{tabular}


A percepção de saúde do adolescente na comunidade pesquisada foi caracterizada em dois opostos: o adolescente estava muito saudável ou muito doente. Enquanto alguns participantes referiram que existia alimentação adequada, outros afirmaram a existência de má alimentação e até mesmo fome na mesma comunidade.

A percepção acerca da realidade de saúde dos adolescentes da comunidade pesquisada conduziu para relação de influência de modo individual de viver na comunidade. A experiência da relação jovem-realidade e jovem-mundo conduz ao desenvolvimento de sua percepção para ação-reação, como também pode tê-las atrofiadas $^{(11)}$.

Identificou-se na maioria dos adolescentes participantes dos grupos: ausência de perspectivas na localidade, desejo de sair da área rural e morar na área urbana. A vivência em uma sociedade economicamente deprimida, com fraca oferta de oportunidades profissionais, provoca efeitos negativos sobre os modos de vida dos adolescentes rurais ${ }^{(14)}$.

O processo de problematização articulado à reflexão seguiu a pergunta-guia: o que então esperar do futuro vivendo em uma comunidade com os problemas apresentados? Em resposta, 18 adolescentes afirmaram que pretendiam sair da zona rural e morar na área urbana.

Esse lugar não tem nada para oferecer para gente. Eu quero ir embora, fazer faculdade e morar sozinha em Fortaleza. (P. 10, F, 14 anos).

Isso cansa muito... é melhor sair e viver sua vida e depois ajudar sua família. (P.21, F, 13 anos).

Eu não sei o que vou ser, mas não quero ficar morando aqui, quero ir embora. (P.09, M, 12 anos).

Observou-se que cinco adolescentes planejavam permanecer na comunidade, no lugar em que nasceram:

Eu quero continuar aqui porque sei que minha mãe não pode pagar uma faculdade para mim e eu não consigo passar na pública. Então, quero um emprego na Fábrica Fortaleza que é aqui perto, é muito boa e eu posso todo dia ir para lá. ( $P$. $16, F, 14$ anos).

Eu não sei para que vocês querem sair daqui e ir para Fortaleza, para o mundo... Pois eu ainda não sei o que quero ser, mas quero ficar aqui e tentar mudar a minha comunidade, trazer as coisas boas para cá. Quando uma pessoa perguntar de onde vocês vieram, vocês vão é ficar com vergonha, e a família de vocês? (P. 23, F, 12 anos).

Surgiu um momento de silêncio e reflexão sobre o assunto. Os facilitadores ficaram surpresos com a indagação da adolescente, a qual propiciou um momento excelente para iniciar um debate sobre o poder do jovem/adolescente para mudar sua comunidade. Abaixo, transcrição do diálogo:

- Vocês acham que podem fazer alguma coisa para melhorar a saúde na comunidade de vocês? (Facilitador).

- Sei lá... Mostrar para todo mundo nas fotos que a gente vai tirar que aqui precisa melhorar! (P. 16, F, 14 anos).

- Mas só mostrar não adianta nada, porque eles já sabem. $A$ gente precisa mudar a cabeça das pessoas que moram aqui que gostam de sofrer. (P.07, F, 17 anos).

- O que a gente pode fazer... é entregar alimentos para pessoas que passam fome aqui. (P. 09, M, 12 anos).

- E a gente compra o alimento com o quê? (Facilitador).

- Com dinheiro. (TODOS).

- E o dinheiro vem de onde? (Facilitador).

- Do trabalho. (TODOS).

- E tem trabalho no Carapió? (Facilitador).

- Não. (TODOS).

- Aqui não tem nada que sustente uma família. (P. 19, F, 15 anos).

- E como a gente poderia tentar mudar isso? (Facilitador).

- Fazendo com que o prefeito botasse mais emprego aqui. (P.16, F, 14 anos).

- Trazendo cursos para gente. (P. 06, F, 17 anos).

A escolha profissional dos adolescentes rurais implica decidir para onde ir e não o que fazer, pois a grande questão é sair ou ficar na área rural(14). Os sentimentos de impotência nestes grupos de adolescentes são expostos ao abraçarem como uma das primeiras alternativas para melhorar a qualidade de vida na sua comunidade, a ideia de abandonar o local onde vivem ${ }^{(15)}$.

A ausência de esperanças de um futuro próximo e não próspero na comunidade conduz o adolescente a não lutar por melhorias e não sentir-se corresponsável por seu meio. A aceitação passiva da realidade é característica da consciência ingênua, uma espécie de quase compromisso com a realidade, as pessoas são conduzidas a assumirem 
uma aceitação do viver na cultura do silêncio, ou seja, a realidade é estática e imutável(16).

No decorrer deste estudo, surgiram falas de participantes que questionaram a necessidade de valorizar o local onde nasceram e onde suas famílias iriam permanecer por muito tempo. Destaca-se, assim, a necessidade de conduzir o grupo na educação para o "empoderamento" e promover a participação e visão ampliada da saúde enquanto cidadão da comunidade ${ }^{(17)}$.

\section{CONSIDERAÇÕES FINAIS}

A compreensão do conceito de saúde para adolescentes pesquisados configura-se como aspecto chave para formulação de políticas públicas na zona rural, as quais devem considerar o papel da família como base educativa e as perspectivas de futuro de jovens/adolescentes na comunidade.

A visão de saúde do adolescente rural sofre influências da realidade econômica vivenciada por suas famílias, ou seja, uma visão mais individual que coletiva, permeada por uma consciência ingênua que entrega o poder de mudança nas mãos dos governantes.

Os problemas de saúde estão relacionados às dificuldades nas áreas social, educacional e recreativa, que vão além do papel do Estado. Estes sinalizam a necessidade de o adolescente rural sentir-se fortalecido para modificar suas perspectivas de vida, sentindo-se como corresponsável pela saúde da comunidade, promovendo a verdadeira mudança social em saúde.

Logo, o enfermeiro pode apropriar-se de uma abordagem sociocultural do adolescer rural que fortaleça as percepções positivas de saúde apresentadas e estimule o potencial do adolescente como ator social. Desta forma, a enfermagem poderá reduzir a distância observada entre a saúde ideal e real na comunidade rural.

\section{AGRADECIMENTOS}

À Profa Dra Maria Grasiela Teixeira Barroso (in memoriam) pelo apoio científico.

2013];45(4);802-10. Disponível em:

http://dx.doi.org/10.1590/S0080-62342011000400002.

8. Wallerstein N, Duran B. Community-based participatory research contributions to intervention research: the intersection of science and practice to improve health equity. Am J Public Health [Internet] 2010 [acesso em: $20 \mathrm{dez}$ 2013];100 Suppl 1:S40-6. Disponivel em:

http://dx.doi.org/10.2105/AJPH.2009.184036.

9. Ministério da Saúde. Estatuto da Criança e do Adolescente [Internet]. $3^{a}$ ed. Brasília: Editora do Ministério da Saúde; 2007 [acesso em: 20 dez 2013]. Disponível em: http://bvsms.saude.gov.br/bvs/publicacoes/lei 8069060117 M.pdf.

10. Ressel LB, Beck CLC, Gualda DMR, Hoffmann IC, Silva RM, Sehnem GD. O uso do grupo focal em pesquisa qualitativa. Texto Contexto Enferm [Internet] 2008 [acesso em: $20 \mathrm{dez}$ 2013];17(4):779-86. Disponível em:

http://dx.doi.org/10.1590/S0104-07072008000400021.

11. Freire P. Conscientização: teoria e prática da libertação. uma introdução ao pensamento de paulo freire. 3.ed. São Paulo: Ed. Moraes; 1980.102 p..

12. Smith R. Spend (slightly) less on health and more on the arts. BMJ [Internet] 2002 [acesso em: 20 dez 2013];325:1432.

Disponivel em: http://dx.doi.org/10.1136/bmj.325.7378.1432. 13. Irvine F. Examining the correspondence of theoretical and real interpretations of health promotion. J Clin Nurs [Internet] 2007 [acesso em: $20 \mathrm{dez}$ 2013];16(3):593-602. Disponível em: http://dx.doi.org/10.1111/j.1365-2702.2005.01539.x.

14. Oliveira ICV, Saldanha AAW. Estudo comparativo sobre a perspectiva de futuro dos estudantes de escolas públicas e privadas. Paidéia (Ribeirão Preto) [Internet] 2010 [acesso em: 20 dez 2013];20(45):47-55. Disponível em:

http://dx.doi.org/10.1590/50103-863X2010000100007.

15. Morais NA, Morais CA, Reis S, Koller SH. Promoção de saúde e adolescência: um exemplo de intervenção com adolescentes 
em situação de rua. Psicol. Soc. [Internet] 2010 [acesso em: 20 dez 2013];22(3):507-18. Disponível em:

http://dx.doi.org/10.1590/S0102-71822010000300011.

16. Freire P. Pedagogia do oprimido. $47^{\text {a }}$ ed. São Paulo: Paz e Terra; 2008.

17. Silva MAI, Mello DF, Carlos DM. O adolescente enquanto protagonista em atividades de educação em saúde no espaço escolar. Rev. Eletr. Enf. [Internet]. 2010 [acesso em: $20 \mathrm{dez}$ 2013];12(2):287-93. Disponível em:

http://dx.doi.org/10.5216/ree.v12i2.5301.

Artigo recebido em 20/08/2012.

Aprovado para publicação em 12/09/2013.

Artigo publicado em 31/12/2013. 